RESUMEN: La breve alusión de Heidegger al amor en Ser y tiempo ha llevado a considerar que es un estado afectivo que no tiene relevancia para el desarrollo de su analítica existenciaria. Sin embargo, a partir de la lectura de Ser y tiempo junto con la correspondencia personal que mantuvo con Hannah Arendt, es posible desvelar el carácter originario del estado amoroso.

PALABRAS ClaVE: Dasein, Hannah Arendt, propiedad, ser con.
ABSTRACT: Heidegger's brief allusion to love in Being and time has led to consider that it is an affective state that has no relevance for the development of his existential analytic. However, from the reading of Being and time along with his personal correspondence with Hannah Arendt, it is possible to reveal the original character of the state of love.

KEYwORDS: being with, Dasein, Hannah Arendt, property. 


\section{HEIDEGGER Y EL ESTADO AFECTIVO DEL AMOR}

En la reconstrucción de la filosofía antigua resultan sumamente importantes los testimonios indirectos y anécdotas que se cuentan en torno a los filósofos, pues permiten reconstruir aspectos de su pensamiento y sus intereses filosóficos. Aunque estas referencias pueden encontrarse más relacionadas con cuestiones de su vida personal, en ocasiones develan aspectos de su reflexión filosófica.

Encontramos el término doxografia por primera vez en Hermman Diels, como título de su investigación Doxographi graeci, ${ }^{1}$ en la cual el helenista alemán reconstruye el pensamiento antiguo en torno a la física, a partir del análisis de comentarios y frag-

${ }^{1}$ Doxographi graeci de Diels fue publicado en Berlín en 1879 en versiones latina y griega, con grabados y a costas de G. Reimeri. mentos de los predecesores de los filósofos griegos. Actualmente se usa para referirse a todo tipo de reconstrucción de las ideas en el estudio de los antiguos, no exclusivamente en el ámbito de la física.

Como ejemplos de los primeros estudios doxográficos en la Antigüedad podemos considerar a Teofrasto, quien recopiló opiniones de los filósofos antiguos en su escrito Opiniones de los físicos, ${ }^{2} \mathrm{y}$ a

${ }^{2}$ Conocemos la obra de Teofrasto por las citas de Simplicio y por su escrito Sobre las sensaciones. En la lista que presenta Diógenes Laercio de las obras de Teofrasto enumera dieciséis libros titulados Opiniones de los filósofos naturales, así como un Compendio de las opiniones de los filósofos naturales. Véase: Diógenes Laercio, Vida y opiniones de los filósofos ilustres, trad. por Carlos García Gual (Madrid: Gredos, 2007), libro V, 48. Al mismo tiempo, Kirk, Raven y Schofield sostienen que su trabajo presenta una gran objetividad. En su primer libro 
Diógenes Laercio, ${ }^{3}$ quien reunió no solo fragmentos y testimonios de sus ideas, sino también anécdotas que ilustran la figura de los pensadores.

De la misma manera, encontramos en los escritos de Platón y Aristóteles una constante referencia no solamente teórica, sino muchas veces comentarios cargados de ironía sobre la vida de los filósofos que les antecedieron. Así, por ejemplo, Platón en el Teeteto 174a narra que Teodoro contaba que una aguda y graciosa esclava tracia se burló de Tales de Mileto, quien por estar observando las estrellas cayó en un pozo. Esta anécdota contada por Platón traza la imagen del filósofo Tales, el primer pensador en estudiar los cuerpos celestes, pero por ser considerado el primer filósofo, al mismo tiempo capta la impresión del filósofo en general: abstraído en sus reflexiones, sin percatarse siquiera de lo que se encuentra a su paso.

De esta manera, la historia de la filosofía se ha nutrido de estos testimonios, que son fuentes valiosas para recuperar el pensamiento antiguo y para conocer a los filósofos como personajes históricos.

organizó a los pensadores a partir de un órden cronológico añadiendo su ciudad, fecha y mutua relación. Este trabajo realizado por Teofrasto fue la fuente de las coleciones posteriores. Véase: G.S. Kirk, J.E. Raven y M. Schofield, Los filósofos presocráticos, trad. por Jesús García Fernández (Madrid: Gredos, 1987).

${ }^{3}$ Diógenes Laercio, Vida de los filósofos ilustres.
Ahora bien, al iniciar la lectura de la correspondencia entre Martín Heidegger y Hannah Arendt una pregunta que me acompaña es qué hay de revelador de su pensamiento en estos escritos, los cuales tienen, sin duda, ante todo, un tinte personal e íntimo.

Heidegger es un filósofo para quien el estudio de la vida cotidiana resultó relevante en su reflexión filosófica. En Ser y tiempo Heidegger inicia planteando la necesidad de reiterar nuevamente la pregunta que interroga por el ser. Considera que esta pregunta ha caído en el olvido, debido a tres prejuicios que ha mantenido la tradición filosófica: ha considerado que "ser" es el más universal, indefinible y comprensible de los conceptos.

La pregunta por el ser se presenta como una condición de posibilidad de todas las demás ciencias. La pregunta ontológica es anterior y es base de todo conocimiento óntico; por ello, para Heidegger, reiterar la pregunta por el ser, que la tradición ha olvidado, resulta una tarea prioritaria en el ámbito de la reflexión filosófica. $\mathrm{Al}$ cuestionar acerca del ser, resalta un ente, el Dasein, que se presenta como señalado para interrogar y dar respuesta a la pregunta. Debido a la preminencia óntico-ontológica del Dasein en relación con la pregunta por el ser, Heidegger considera necesario, previo a la pregunta, un análisis ontoló- 
gico de las estructuras fundamentales de aquel que se cuestiona y quien, por lo tanto, puede brindar una respuesta. Así, la analítica existenciaria, el estudio de las estructuras fundamentales del vivir cotidiano del Dasein, se revela como el camino de acceso a la pregunta por el ser. "La pregunta por la vida fáctica no debe ser considerada de manera independiente de la pregunta por el ser en general, sino solo en el camino de aseguramiento del planteamiento de esta pregunta principal". ${ }^{4}$

En este sentido, el desvelamiento de las estructuras fundamentales de la vida cotidiana del Dasein se convierte en la condición de posibilidad de la investigación ontológica. Ahora bien, el tema que me ocupa en este escrito forma parte de lo que podríamos considerar asuntos de la vida privada del filósofo.

Para la recuperación del pensamiento de Martin Heidegger contamos no solo con su obra Ser y tiempo, uno de los escritos ejes de su reflexión, sino con la publicación en marcha de sus obras completas que contiene, además de todos sus escritos, los cursos y conferencias que el filósofo dictó.

Respecto de su vida, tenemos acceso a la correspondencia personal

${ }^{4}$ Ángel Xolocotzi, Fenomenología de la vida fáctica. Heidegger y su camino a Ser y tiempo (México: UIA/Plaza y Valdés, 2004), 202. que mantuvo, entre otros, con Karl Jaspers, Rudolph Bultmann, su hermano Fritz, su esposa Elfride y Hannah Arendt. Dado que el pensamiento de Heidegger ha marcado el quehacer filosófico a lo largo del siglo XX, su vida ha generado un profundo interés y ha sido fuente de intensas polémicas, debido a que se ha considerado que sus decisiones en el ámbito de la vida pública no han estado a la altura de su pensamiento.

Estudiosos como Otto Pöggeler, 5 François Fédier ${ }^{6}$ y Philipp LacoueLabarthe $^{7}$ han reflexionado de forma crítica sobre las decisiones políticas que Heidegger tomó durante el gobierno del Tercer Reich, tales como aceptar el rectorado de la Universidad de Friburgo en 1933, pronunciar un discurso de rectorado en el que asumió una posición política frente a la situación de Alemania, afiliarse al partido nacionalsocialista, mantener una relación distante con sus colegas judíos y su maestro Husserl durante este periodo y el silencio que le seguirá.

Víctor Farías, en Heidegger y el nazismo, uno de los críticos más fuertes de Heidegger, ha pretendido leer

${ }^{5}$ Me refiero al escrito traducido al español como Filosofia y politica en Heidegger, en el que Pöggeler abunda en la dimensión política de la reflexión realizada por Heidegger en torno a la pregunta sobre el habitar del hombre en la tierra.

${ }^{6}$ François Fédier, Heidegger: Anatomie d'un scandale (París: Robert Laffont, 1988).

${ }^{7}$ Philipp Lacoue-Labarthe, Heidegger: La política del poema (Madrid: Trotta, 2007). 
su obra a partir de las conclusiones que ha sacado de su biografía. Farías concluye que en la vida de Heidegger hay elementos que corresponden a una ideología nacionalista, xenófoba y autoritaria, de tal suerte que sus escritos pueden ser leídos siguiendo esta línea interpretativa y cada dato biográfico del filósofo justifica esta conclusión.

Ante esta visión, un tanto errada, de vincular vida y pensamiento en Heidegger desde una dirección muy precisa, Aubenque en su artículo "Otra vez Heidegger y el nazismo" considera que Farías, después de la lectura y consulta de múltiples archivos, tenía elementos para escribir una biografía de Heidegger; sin embargo, parece claro que no era lo que le interesaba, sino elaborar un documento que demostrara su ideología nazi. ${ }^{8}$

El libro de Farías constituye un problema ya por su misma existencia. No es un libro de filosofía. Los débiles análisis a los que se entrega son demasiado breves o francamente erróneos. Uno se pregunta - ha dicho con justicia J. Derrida a propósito de él- "si ha leído a Heidegger más de una hora". Mas se dirá tal vez que es un libro de historia. No lo creo, no solo porque está lleno de errores, sino porque su fin único y confesado es presentar una requisitoria. ${ }^{9}$

${ }^{8}$ Pierre Aubenque, “Otra vez Heidegger y el nazismo", Revista de Filosofía 1 (1987-1988): 158. ${ }^{9} \mathrm{Ibid}$.
De esta manera, resulta un tanto problemático y otras veces decepcionante aproximarse a la vida de un pensador con la intención de encontrar una guía de lectura de su obra o de observar el esplendor de su pensamiento. Heidegger se ocupó de reflexionar en torno a la vida cotidiana, pero tal vez descuidó su hacer cotidiano. Sin duda, el pensamiento filosófico de Martin Heidegger marca las líneas de reflexión a partir de las cuales y contra las cuales se desarrollará la filosofía del siglo XX, pero también nos ha dejado aspectos de su vida que causan gran extrañeza y parecen alejados de una reflexión profunda.

Heidegger, una referencia fundamental en todo el siglo XX intelectual, y sus compromisos ideológicos e institucionales, que al menos a comienzos de la década de 1930, e incluso hasta el fin de la guerra, acoplaron ese mismo nombre propio a la política nacional socialista y/o al Estado nazi, sin que el filósofo haya ofrecido una explicación valiente..$^{10}$

Otro de los aspectos que nos ha dejado Heidegger para la discusión es la relación que mantuvo con las mujeres. Es un tema que han investigado de forma rigurosa Alan Badiou, Barbara Cassin, Ángel Xolocotzi y Luis

${ }^{10}$ Alain Badiou y Barbara Cassin, Heidegger. El nazismo, las mujeres, la filosofia (Buenos Aires: Amorrortu, 2011), 9. 
Tamayo, ${ }^{11}$ a partir de un análisis de su correspondencia personal.

A lo largo de este escrito mí me interesa reconstruir la concepción heideggeriana del estado afectivo del amor, a partir de la correspondencia personal que mantuvo con Hannah Arendt y de la lectura de Ser y tiempo. En Ser y tiempo tan solo encontramos una alusión a pie de página, pero es un tema latente en la correspondencia que intercambió con Hannah Arendt entre 1925 y 1975.

El intercambio que mantuvieron Heidegger y Arendt durante 50 años devela una relación que se distingue de las aventuras amorosas que tuvo Heidegger a lo largo de su vida, no solo porque Arendt perduró, sino porque fue una interlocutora constante de su pensamiento y una artífice vital para la publicación de sus escritos. ${ }^{12}$

${ }^{11}$ En el escrito Los demonios de Heidegger: Eros y manía en el maestro de la Selva Negra, Ángel Xolocotzi y Luis Tamayo reconstruyen las distintas facetas de la vida amorosa y las afecciones físicas y emocionales de Heidegger.

${ }^{12}$ Heidegger, en la carta del 21 de abril de 1954, agradece a Arendt la revisión de la traducción de Ser y tiempo que elabora Robinson y posteriormente ella confirma, una revisión extremadamente precisa del manuscrito de traducción. El 20 de abril de 1969 Elfriede y Heidegger escriben a Arendt para consultarla sobre la venta del manuscrito autografiado de Ser y tiempo. El 21 de febrero de 1972 Arendt informa a Heidegger acerca de la propuesta de Wolf Jobst Siedler de publicar una edición de las obras completas de Heidegger, sugerencia que el 10 de marzo de 1972 Heidegger rechaza por considerarlo un clasismo. El 27 de marzo de 1972 Heidegger le pregunta a Arendt qué hacer con los apuntes de los cursos de Marburgo que posee Heinz Lichtenstein
En Ser y tiempo (\$ 29) Heidegger analiza el fenómeno del "encontrarse" (Befindlichkeit), el cual se revela como un carácter ontológico del Dasein que en un sentido óntico refiere al "temple anímico" (Stimmung), en el cual el Dasein se encuentra de forma inmediata y cotidiana en su "ser-en-elmundo".

Heidegger inicia el análisis del encontrarse con un recorrido histórico del tratamiento de los pathé, las pasiones o afectos. Considera que este análisis se ha limitado, desde Aristóteles hasta la modernidad, a ser un estudio ontológico muy básico. Por una parte, considera positivo el interés de la escuela fenomenológica $y$, por la otra, considera el impulso que dieron San Agustín y Pascal a la cuestión. Como referencia, Heidegger presenta, a pie de página, una cita de San Agustín, en la cual el filósofo de Hipona cita un proverbio, según el cual para amar las cosas es necesario conocerlas; sin embargo, sostiene que para acceder al conocimiento de las cosas divinas los santos recorren un camino inverso: para ellos, el amor es una condición previa para llegar a

que van del 1925 a 1929. Entre estos cursos se encuentran: Semestre de invierno 1924-1925: Sofista, Semestre de verano 1925: Concepto del tiempo, Semestre de invierno 1925/1926: Lógica, Semestre de verano 1927: Problemas fundamentales de la fenomenología, Semestre de invierno 1928-1929: Introducción a la filosofía. 
su conocimiento. De esta manera el temple anímico del amor se convierte en el acceso al conocimiento y la verdad. "[C]e qui a passé en proverbe, les saints au contraire disent en parlant des choses divines qu'il faut les aimer pour les connaître, et qu' on n' entre dans la vérité que par la charité."13

Esta cita indirecta (ya que es por medio de Pascal ${ }^{14}$ que Heidegger se refiere a la frase de San Agustín: "non intratur in veritatem, nisi per caritatem") ${ }^{15}$ es la única referencia que se realiza en Ser y tiempo al temple anímico del estado amoroso. En ella se destaca la capacidad de apertura que tiene esta afección en quien la padece, al permitirle conocer la cosa y por ello llegar a la verdad. Posteriormente, Heidegger desarrolla su análisis de la angustia, la cual tiene un lugar privilegiado entre los distintos estados anímicos.

La angustia es un temple fundamental que al mismo tiempo que descoloca al Dasein de la familiaridad comprensora de su "ser-en-el-mundo", lo sitúa ante su totalidad estructural

\footnotetext{
${ }^{13}$ Heidegger, El ser y el tiempo, trad. por José Gaos (México: FCE, 1988), § 29, 156, n. 2.

${ }^{14}$ Blaise Pascal, "De l'esprit géométrique, section II : De l'art de persuader", en Pensées et opuscules, ed. por Léon Brunschvicg (París: Hachette, 1912), 185.

15 "No se penetra en la verdad más que por el amor." San Agustín, Contra Faustum, lib. 32, cap. 18.
}

original de la cura en cuanto "pre-serse" y le abre la posibilidad de una existencia propia.

De esta manera, la exploración que Heidegger realiza del estado anímico del amor en San Agustín representa un antecedente de la investigación de los estados anímicos realizado por la tradición filosófica y un impulso en Ser y tiempo para la investigación que desarrollará más adelante sobre la angustia como un estado afectivo fundamental (Grundstimmung).

Hannah Arendt, por su parte, dedicó su investigación de doctorado, dirigida por K. Jaspers en la Universidad de Heidelberg y defendida en 1928, a una "interpretación comprensiva" del concepto del amor en San Agustín.

Así, en la segunda carta que Heidegger dirige a Arendt, el 21 de febrero de 1925 , se refiere al amor como aquello que supera todas las dimensiones de las otras posibilidades humanas.

Para entender el sentido de esta superación es preciso avanzar unas líneas más adelante y rescatar los conceptos de "yo" y "otro". Heidegger observa en este estado afectivo que el yo se coloca frente a un tú y que para amarlo requiere superar el ámbito de lo propio. Gracias al estado afectivo del amor el "yo" rompe los límites de lo que le es más próximo, su ser mismo, para acceder a aquello 
que, en la cercanía aparece como lo más lejano, el "otro".

Para Heidegger el amor supone una conversión. El que ama - dice Heidegger - se transforma en lo amado sin dejar de ser él mismo. En este sentido, el estado afectivo del amor lleva a quien lo padece tanto a una ruptura como a una conservación: el yo rompe sus límites y se convierte en lo otro, pero al mismo tiempo, solo puede llegar a ser lo otro sin renunciar de forma absoluta a ser sí mismo.

Por otra parte, en este estado afectivo, Heidegger considera que acontece una entrega, en la cual los que se aman brindan al otro el destino de su vida. Esta entrega al otro es observada como una donación.

Para interpretar los conceptos de destino y de donación conviene recurrir al $\S 42$ de Ser y tiempo, dedicado al estudio de la "cura". Para explicar la noción de "cura" Heidegger presenta un mito transmitido por Higinio y traducido por Burdach, según el cual cierto personaje, "Cura", dio origen al ser humano.

La narración que Heidegger presenta como una antigua fábula comienza con la llegada de Cura a un río, donde tras observar pedazos de tierra húmeda comienza a modelar algo. Del trozo de arcilla modelado surge el ser humano. Al ver Cura el modelo de arcilla le pide a Júpiter que le infunda espíritu. Luego, al querer darle nombre a su creación entra en disputa con
Júpiter, solo que interfiere Tierra que, al haber donado la materia para su creación, considera justo que lleve su nombre. Saturno es elegido juez de la disputa y dictamina que el ser humano, al estar hecho de "humus", no solo será nombrado "homo" en honor a la Tierra, sino que también Tierra recibirá su cuerpo cuando muera. Por su parte, Cura, al haberle dado forma, lo acompañará durante su vida, mientras que Júpiter recibirá su espíritu al morir.

A partir de este mito, Heidegger caracteriza el ser del Dasein como "cura". El Dasein al existir es apertura de comprensión e interpretación de todo lo existente. El Dasein al encontrarse en el mundo comprende su ser, el ser de los otros y el de los entes intramundanos a partir de las posibilidades que le son propias.

De esta manera, el Dasein, al ser apertura de manifestación de todo lo existente, tiene una responsabilidad no solo de su ser, sino del ser en general. En este sentido, la noción de "cura" expresa el destino y la donación en la que el Dasein, al existir, se encuentra convocado por todo lo existente. En la forma cotidiana, regular e inmediata, el Dasein comprende e interpreta los entes intramundanos como "ser a la mano" y "ser ante los ojos". Se cura del mundo haciendo uso de los entes, utilizándolos o analizándolos; pero al mismo tiempo, 
esta experiencia cotidiana del mundo circundante representa la posibilidad de una comprensión e interpretación apropiativa de su existencia y de su "ser-en-el-mundo". Burdach llama la atención sobre un doble sentido del término "cura", según el cual no solo significa "esfuerzo angustioso", sino también "solicitud", "entrega". ${ }^{16}$

Posteriormente, en la carta a Arendt del 13 de mayo de 1925, Heidegger cita nuevamente a San Agustín y considera que el estado amoroso implica estar empujado a la existencia más propia.

En el $\S 40$ de Ser y tiempo, Heidegger analiza el estado fundamental del "encontrarse de la angustia" como un estado que posibilita al Dasein tornar a una existencia propia.

El Dasein en su ser cotidiano se encuentra ya caído "en el mundo", comprendiéndolo e interpretándolo desde la forma de ser de lo a la mano, a partir de la cual los entes se presentan como objetos de uso, que pueden ser empleados. Sin embargo, cada ente se encuentra inmerso en una serie de relaciones y referencias con otros entes, de tal manera que su "ser a la mano" supone una pre-comprensión del todo significativo del "ser en el mundo", el cual es siempre ya un "ser con los otros". A esta forma cotidiana de "ser en el mundo" haciendo uso de

\footnotetext{
${ }^{16}$ Heidegger, El ser y el tiempo, $\S 42,219$.
}

los entes intramundanos y de encontrarse comprendiendo el mundo a partir de interpretaciones heredadas, Heidegger le nombra "la caída". Ella es el modo de conducirse cotidiano e inmediato del Dasein en el mundo, caracterizado por la impropiedad. La impropiedad no tiene un carácter despectivo, es el modo inmediato del Dasein en el mundo de comprender e interpretarlo a partir de lo ya interpretado por otros y representa la posibilidad de apropiarse de su "ser en el mundo".

Heidegger considera que ante este estado de caída cotidiano, el Dasein se encuentra absorbido dentro del uno, comprendiendo e interpretando los entes intramundanos y su ser a partir de lo ya establecido por los otros, de tal manera que el estado de la angustia es una posibilidad de acceder a un estado de propiedad, es decir, a que el Dasein se separe de la interpretación impropia de lo uno y a partir del reconocimiento de su carácter finito comprenda e interprete el mundo desde sí mismo.

El ante qué de la angustia no es algo particular, la radicalidad de este estado afectivo se encuentra en que precisamente se desconoce aquello ante lo cual el Dasein se angustia. E1 ante qué de la angustia al mismo tiempo que es el "ser en el mundo" en su totalidad, es la nada. En el estado de 
la angustia se fractura el todo significativo del mundo, de tal manera que toda la serie de significados a partir de los cuales el Dasein había interpretado el "ser en el mundo" se muestran como sin sentido y el mundo en su totalidad resulta inhóspito, carente de confort y seguridad. Pese a que la angustia no es un estado placentero para el Dasein, tiene un aspecto ontológico positivo, singulariza al Dasein, al desvelarle su carácter finito de "ser para la muerte" y, por lo tanto, las posibilidades de elegirse a sí mismo. "La angustia singulariza y abre así el Dasein como 'solus ipse'. Pero este solipsismo existenciario está tan lejos de instituir una cosa-sujeto aislada en el inocuo vacío de un tener lugar sin mundo, que pone al 'ser ahí' justamente en un sentido extremo ante su mundo como mundo y con ello ante sí mismo como "ser en el mundo". ${ }^{17}$

De esta manera, mientras la angustia individualiza al Dasein y lo conduce a sus límites al hacer patente su temporalidad, en tanto "ser para la muerte", el amor por su parte, contrariamente al "solus ipse" de la angustia, presenta al Dasein ante sus límites de "ser con".

En el estado afectivo del amor, el Dasein se encuentra volcado a "otro" Dasein. Pero el "otro", al mismo tiempo que se presenta como

${ }^{17}$ Ibid., § 40, 208. un doble de él mismo, se manifiesta bajo su carácter de ser un Dasein distinto al "yo". Si bien el Dasein se encuentra inmediata y regularmente en el mundo usando los entes intramundanos y comprendiendo e interpretándolo a partir de la utilidad, el carácter del "ser con" lo coloca ante la igualdad del ser del "otro", de tal manera que no puede reducirlo a un objeto o un útil, el "otro" tiene el mismo carácter de ser del Dasein.

Así, el "ser con" se encuentra dirigido por una proyección del Dasein hacia el otro, comprendiéndolo como alguien idéntico, pero al mismo tiempo diferente a sí mismo.

En el $§ 26$ de Ser y tiempo Heidegger analiza la forma cotidiana del Dasein del "ser con". El "ser con" refiere a un carácter inherente al $D a$ sein que expresa la relación ontológica que mantiene al "ser en el mundo" con otros entes de su misma especie.

El "ser en el mundo" es siempre ya ontológicamente compartido con otros Dasein. El "ser con" se diferencia del "ser a la mano" y del "ser ante lo ojos", porque los entes con los cuales se enfrenta no pueden ser reducidos al útil o al objeto que es observado: los otros son ontológicamente similares. Ahora bien, la forma peculiar de relación que guarda ontológicamente el Dasein con los otros es el "procurar por" ellos. El "procurar 
por" en la forma cotidiana presenta modos deficientes; pero también otros positivos.

El "ser uno sin el otro", "contra el otro", "pasar de largo junto a otro" o "no importarle uno a otro", son formas deficientes de "ser con", en las que el otro parece no importar. Estas formas de relación cotidiana, pese a la indiferencia que revelan, hacen patente la estructura ontológica de un ser al que le es propio el "ser uno con el otro".

Por otra parte, los modos positivos del "procurar por" el otro, son considerados como posibilidades extremas de relación con el otro. La primera consiste en arrebatar al "otro" su "curarse del mundo" poniéndose en su lugar, haciendo uso de los entes para la realización u obtención de algo, y una vez terminado este proceso, poner a disposición del Dasein aquello que resultó, es decir, aquello de lo cual "se curó". El otro modo positivo del "procurar por" consiste en ayudar al otro a apropiarse de su ser a partir de permitirle quedar en libertad para realizarla. Esta última forma le devuelve al Dasein su cura y "procura por" él para que pueda abrirse a las posibilidades de su existencia. "Según el análisis acabado de hacer, es inherente al ser del 'ser ahi' el irle en su ser mismo el 'ser con' otros. En cuanto 'ser con', es, por ende, el 'ser ahí' esencialmente 'por mor de otros". 18

Ahora bien, Heidegger reflexiona acerca de la relación sentimental que se puede establecer con el otro y considera que ella no nombra un fenómeno original existenciario, sino que se asienta sobre la base del "ser con", representando una posibilidad del Dasein cuyo peculiar ser es siempre ser con otro.

La forma cotidiana y general en la que el Dasein es con los otros se caracteriza por eliminar las particularidades y diferencias existentes entre los unos y los otros, de tal manera que el Dasein queda subsumido en el anonimato del uno. En el ser uno con otro, el uno es la forma dominante de relación, el Dasein realiza actividades y se relaciona uno con el otro como se hace.

Ahora bien, aunque la relación sentimental es un estado derivado del fenómeno originario del "ser con" y del "encontrarse", el estado amoroso representa una posibilidad para el Dasein de acceder a la apropiación de su ser en la medida en que en el estado amoroso el Dasein, en cierto sentido, sale fuera de sí, la comprensión y el impulso de convertirse en el otro representa, al mismo tiempo que el límite para el Dasein, la posi-

${ }^{18}$ Ibid., $\S 26,139$. 
bilidad de apropiarse de su existencia, es decir, de vislumbrar y tomar de las posibilidades que le son propias. Si bien el "ser con" es un existenciario, en la forma cotidiana el Dasein se relaciona con el "otro" a partir de las formas de relación dominantes del uno; sin embargo, el estado anímico del amor conduce a singularizar lo amado, a ver lo otro como "único", lo cual distingue este estado de las formas positivas y negativas de relación del Dasein con los otros.

En el estado amoroso el Dasein no le da ni le quita al otro su "cura", sino que desea que el otro sea lo que es. "Solo aquí todo significa: estar en el amor = estar empujado a la existencia más propia. Amo significa volo, ut sis, dice San Agustín en un momento: te amo - quiero que seas lo que eres". ${ }^{19}$ 